\title{
Rheumatoid pneumoconiosis in association with asbestosis
}

\author{
W. K. C. MOR G A N \\ From the University of Maryland School of Medicine. Baltimore 1, Maryland
}

In 1953 a new syndrome was described in which the association of rheumatoid arthritis with nodular fibrosis of the lung parenchyma was noted (Caplan, 1953). Though this condition resembles progressive massive fibrosis in some ways, there are certain distinctive features. The opacities that are found in Caplan's syndrome are usually more peripherally situated, tend to be multiple, and more commonly affect both lungs. The unusual radiological features that lead to the recognition of the syndrome were originally observed in a group of coal-miners with rheumatoid arthritis, though since then the syndrome has been described in other pneumoconioses, including asbestosis (Rickards and Barrett, 1958 ; Tellesson, 1961 ; Campbell, 1958). Furthermore, it is now realized that occasionally the parenchymal nodules may precede the development of arthritis by several years.

This case report has several unusual and interesting features: first, detailed pulmonary function studies and a lung biopsy were performed ; secondly, the subject had no overt evidence of rheumatoid arthritis; and lastly, the biopsy revealed the presence of asbestosis, an occupational hazard not to be expected in a man who had been an arc-welder all his life.

\section{CASE REPORT}

A 49-year-old man was admitted to Maryland General Hospital with complaints of cough and mild shortness of breath on exertion. He had been well until two months before admission when these symptoms had developed insidiously, and consequently he had been referred as an outpatient for a chest radiograph. This had shown some reticulo-nodulation in the mid and lower zones and several discrete rounded nodules in both lung fields (Fig. 1). Because of these findings he was admitted for investigation. The only other pertinent fact in his history was that he had been an electric arc-welder for 20 years and had worked in both confined and open spaces.
Physical examination was unrevealing apart from mild clubbing. His respiratory rate was 26 per minute, but there was no evidence of dyspnoea and his chest was remarkable for the absence of other physical signs. There was no evidence of rheumatoid arthritis. Laboratory investigations were likewise unrevealing. A complete blood count, urinalysis, sputum, and electrocardiogram were normal. The E.S.R. (Wintrobe) was significantly raised on two occasions. An intermediate purified protein derivative skin test was positive, but the histoplasmin skin test was negative. Tomography added no additional information.

It was therefore decided to obtain a lung biopsy for diagnostic purposes. Accordingly, a left thoracotomy was performed by Dr. John Miller. The lung was found to contain multiple small millet-seed nodules, but in addition several larger nodules were palpable, the largest being about the size of a table-tennis ball. A wedge of the lung parenchyma and a nodule were resected. The histological appearances were the cause of considerable consternation. There was a fair amount of iron present in the lung parenchyma, such as is seen in welders' siderosis, but surprisingly, the lung parenchyma also showed evidence of interstitial fibrosis, and furthermore numerous asbestos bodies could be seen. The histological appearance of the nodule was perplexing but was thought probably to be due to an unusual response to the inhalation of asbestos. A retrospective occupational history explained the presence of the asbestos fibres. The patient had welded pipes in the interior of ships for many years, and the pipes were lagged with asbestos. Welding and lagging proceeded simultaneously, and the latter inevitably produced a 'snow storm' of asbestos fibres.

Three months after thoracotomy the patient was referred to the Pulmonary Function Laboratory at University Hospital to determine whether he had respiratory insufficiency. At this time the diagnosis of Caplan's syndrome was considered, and a latex fixation test was performed and found 


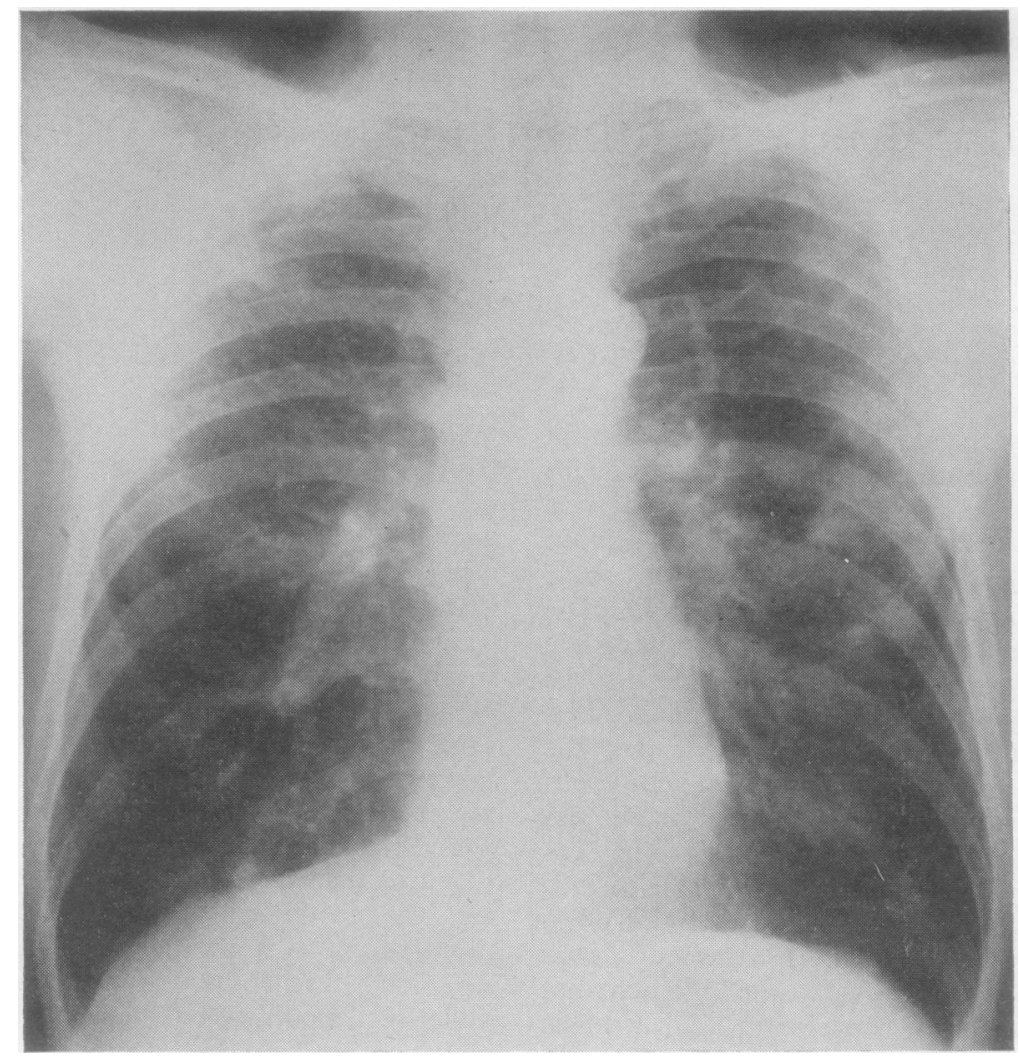

FIG. 1. Chest radiograph showing reticulation and also the presence of larger nodules.

to be positive to a dilution of $1: 1,250$. The pulmonary function studies obtained at this time are shown in Tables I and II. They demonstrate an increased residual volume, functional residual capacity, and total lung capacity with no significant airway obstruction. The arterial blood studies show a normal saturation with a marked reduction of the $\mathrm{PCO}_{2}$ level. This indicates marked

T A B L E I

PULMONARY FUNCTION STUDIES

\begin{tabular}{|c|c|c|c|c|}
\hline & & Predicted & Observed & $\%$ \\
\hline 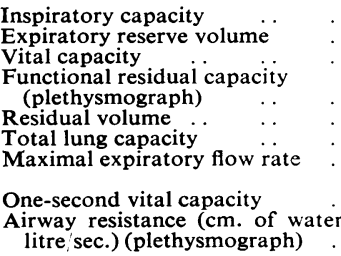 & $\begin{array}{l}\ldots \\
\ldots \\
\ldots\end{array}$ & $\begin{array}{l}3,450 \mathrm{ml} \\
1,150 \mathrm{ml} . \\
4,600 \mathrm{ml} \\
2,550 \mathrm{ml} \\
1,400 \mathrm{ml} . \\
6,000 \mathrm{ml} . \\
300-500 \\
1 . \mathrm{min} . \\
81 \% \\
<2.0\end{array}$ & $\begin{array}{l}2,800 \mathrm{ml} \\
1,700 \mathrm{ml} . \\
4,500 \mathrm{ml} \\
4,300 \mathrm{ml} \\
2,600 \mathrm{ml} \\
7,100 \mathrm{ml} \\
6901 . \mathrm{min} \\
82 \% \\
0.95\end{array}$ & $\begin{array}{r}81 \\
149 \\
98 \\
\\
167 \\
186 \\
118\end{array}$ \\
\hline
\end{tabular}

TABLE II

PULMONARY FUNCTION STUDIES

\begin{tabular}{|c|c|c|c|c|c|}
\hline & & & & Predicted & Observed \\
\hline 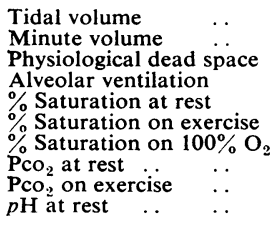 & $\begin{array}{l}\cdots \\
\cdots \\
\cdots \\
\cdots \\
\cdots \\
\cdots \\
\cdots \\
\cdots\end{array}$ & $\begin{array}{l}\cdots \\
\cdots \\
\cdots \\
\cdots \\
\cdots \\
\cdots \\
\cdots \\
\cdots \\
\cdots\end{array}$ & $\begin{array}{l}\cdots \\
\cdots \\
\cdots \\
\cdots \\
\cdots \\
\cdots \\
\cdots \\
\cdots\end{array}$ & $\begin{array}{l}500 \mathrm{ml} \\
7 \cdot 01 . \\
150 \mathrm{ml} \\
4 \cdot 81 \\
96 \\
>96 \\
100 \\
38-42 \mathrm{~mm} . \\
38-42 \mathrm{~mm} . \\
7 \cdot 38-7 \cdot 42\end{array}$ & $\begin{array}{l}1,200 \mathrm{ml} \\
27.61 . \\
720 \mathrm{ml} \\
111 . \\
96.4 \\
97 \cdot 9 \\
100 \\
29 \mathrm{~mm} . \\
29 \cdot 8 \mathrm{~mm} . \\
7.47\end{array}$ \\
\hline
\end{tabular}

hyperventilation and implies either that the sub- N ject was anxious and hence hyperventilating or, much more probably in view of the histological findings of interstitial fibrosis, that he could only maintain his oxygen saturation at normal levels by hyperventilating; in short, he had alveolarcapillary block. By now it was strongly suspected that the patient had anarthritic rheumatoid pneumoconiosis, and accordingly the sections of the nodule and lung were forwarded to Professor 


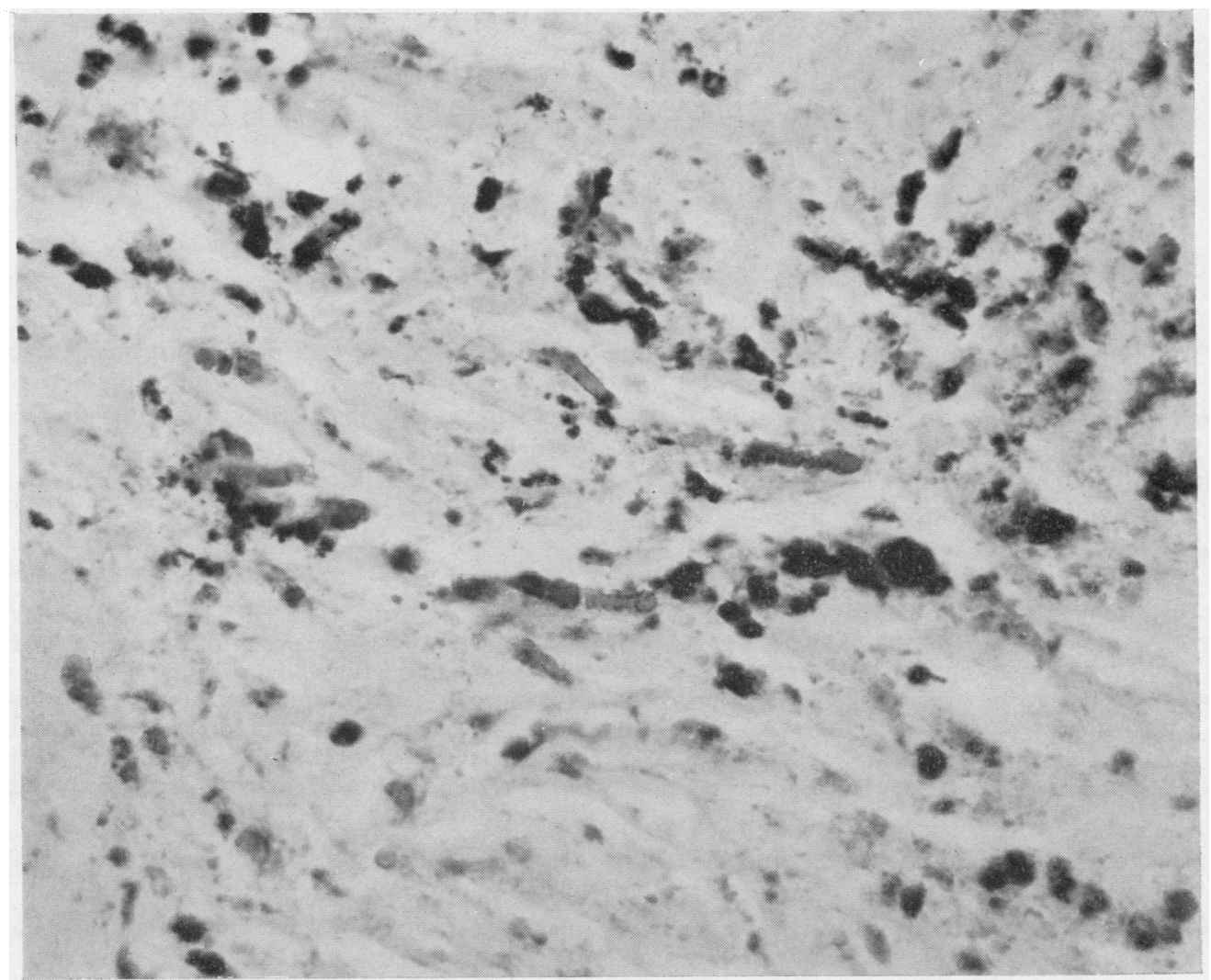

FIG. 2. Photomicrograph showing asbestos bodies. H. and E., $\times 600$.

Jethro Gough for his opinion (Fig. 2). He considered that this was a further instance of Caplan's syndrome associated with asbestosis, and thought that the resected nodule demonstrated the usual findings of this condition.

\section{COMMENT}

So far as is known, this is only the third time that rheumatoid pneumoconiosis has been reported in association with asbestosis. Adequate descriptions of the microscopic findings in rheumatoid pneumoconiosis complicating asbestosis are available elsewhere (Rickards and Barrett, 1958 ; Tellesson, 1961), and in addition a complete and lucid account of the general pathology of Caplan's syndrome has been published (Gough, Rivers, and Seal, 1955). It seems unnecessary to describe in detail the microscopic findings in this case, as in this instance there seems little doubt of the diagnosis in view of the positive serological findings and the characteristic histological appearances.
This patient was one of several other subjects with welders' siderosis who had detailed pulmonary function studies performed and who have been reported in a different context elsewhere (Morgan and Kerr, 1963). Consideration of the difficulties encountered here in making a diagnosis shows how hazardous it is to suggest clinical or radiological diagnoses without adequate physiological and pathological studies.

I am indebted to the Editor of the Annals of Internal Medicine for kindly allowing me to reproduce Fig. 2 and to Professor Jethro Gough for his opinion on the slides.

\section{REFERENCES}

Campbell, J. A. (1958). A case of Caplan's syndrome in a boiler-scaler. Thorax, 13, 177 .

Caplan, A.'(1953). Certain unusual radiological appearances in the chest of coal-miners suffering from rheumatoid arthritis. Ibid., 8 29.

Gough, J., Rivers, D., and Seal, R. M. E. (1955). Pathological studies of modified pneumoconiosis in coal-miners with rheumatoid arthritis (Caplan's syndrome). Ibid., 10, 9.

Morgan, W. K. C., and Kerr, H.D. (1963). Pathologic and physiologic studies ố welders' siderosis. Ann. intern. Med., 58, 293.

Rickards, A. G., and Barrett, G. M. (1958). Rheumatoid lung changes associated with asbestosis. Thorax, 13, 185 .

Tellesson, W. G. (1961). Rheumatoid pneumoconiosis (Caplan's syndrome) in an asbestos worker. Ibid., 16, 372. 